\title{
Brief Report: Preferred Processing of Social Stimuli in Autism: A Perception Task
}

\author{
A. Meermeier ${ }^{1}(1) \cdot$ M. Jording ${ }^{1,2} \cdot$ Y. Alayoubi ${ }^{1} \cdot$ David H. V. Vogel $^{1,2} \cdot$ K. Vogeley $^{1,2} \cdot$ R. Tepest $^{1}$
}

Accepted: 8 July 2021 / Published online: 16 September 2021

(c) The Author(s) 2021

\begin{abstract}
In this study we investigate whether persons with autism spectrum disorder (ASD) perceive social images differently than control participants (CON) in a graded perception task in which stimuli emerged from noise before dissipating into noise again. We presented either social stimuli (humans) or non-social stimuli (objects or animals). ASD were slower to recognize images during their emergence, but as fast as $\mathrm{CON}$ when indicating the dissipation of the image irrespective of its content. Social stimuli were recognized faster and remained discernable longer in both diagnostic groups. Thus, ASD participants show a largely intact preference for the processing of social images. An exploratory analysis of response subsets reveals subtle differences between groups that could be investigated in future studies.
\end{abstract}

Keywords Social stimuli $\cdot$ Perception task $\cdot$ Autism spectrum disorder $\cdot$ Image recognition $\cdot$ Image persistence

The question whether persons with autism spectrum disorder (ASD) experience social stimuli differently than control persons without ASD (CON) has been widely debated. In non-autistic persons there is a very stable preference for processing social stimuli (depicting humans, i.e. faces and body parts), either reflected in shorter reaction times in a detection task for faces and body parts (Ro et al., 2007) or a better detection or discrimination of social stimuli (Bruce et al., 1991; Kikuchi et al., 2009; Lehky, 2000; Ro et al., 2001). Briefly presented faces are detected faster and more accurately than objects (Purcell \& Stewart, 1988) and salient social stimuli (i.e. upright faces) can get access to consciousness faster than less salient stimuli (i.e. upside-down faces, Jiang et al., 2007).

In ASD visual attention towards social stimuli seems to be decreased compared to control persons (Chita-Tegmark, 2016; Frazier et al., 2017). Changes in social stimuli were not faster detected than changes in object stimuli by children with ASD in contrast to their healthy peers (Kikuchi et al., 2009). Social stimuli in comparison to non-social stimuli

A. Meermeier

annegret.meermeier@uk-koeln.de

1 University Hospital Cologne, NRW, Kerpener Strasse 62, Geb. 31, 50931 Cologne, Germany

2 Forschungszentrum Jülich, INM3, NRW, Wilhelm-Johnen-Straße 1, 52428 Jülich, Germany interfere more with a Stroop-task for typically developing children in contrast to children with ASD (Chevallier et al., 2013). Impairments of the ability to recognize faces have been observed in persons with ASD, but here results were less consistent and partially even contradictory (Guillon et al., 2016; Tang et al., 2015; Weigelt et al., 2013). When presented with social stimuli for very brief time spans persons with ASD tended to report less accurately on the gist of the scene (Vanmarcke et al., 2016a) or the kind of interaction (Vanmarcke et al., 2016b) compared to control persons while no differences were observable for non-social stimuli.

However, the question remains, whether these behavioral differences associated with ASD result from a decreased preference for processing and thus recognition of social stimuli or from correct recognition but less relevance attribution and thus attention towards social stimuli in ASD or both.

To investigate the ability to recognize visual stimuli in ASD and to test whether social stimuli are processed preferentially in ASD we have constructed two different perception tasks. In the first task, we investigated how quickly individuals with and without ASD accurately recognize social and non-social images appearing from noise. Therefore, we presented stimuli depicting mere noise gradually resolving over $8 \mathrm{~s}$, revealing either social (containing one or several humans) or non-social scenes (objects or animals). All stimuli were created so that 
potential systematic differences in low-level image features between social and non-social images were reduced to a minimum. We assessed at which point in time - corresponding to different levels of noise - participants correctly recognized the scene. We expected that social stimuli would be recognized earlier than non-social stimuli when emerging from noise. We did not expect any differences between the two diagnostic groups in their mean recognition times, but the difference in recognition times between social and non-social stimuli was hypothesized to be less pronounced in persons with ASD.

In a second task, images disappeared into noise (i.e., gradually turning from a recognizable image into noise over $8 \mathrm{~s}$ ) and participants had to report the point in time at which they were no longer able to recognize the image anymore. This task allowed us to rule out influences of potential differences in response times in participants with ASD and to control for potential effects of stimulus familiarity and stimulus heterogeneity. Given the high relevance of social information in everyday life, we predicted a generally more stable persistence of social images in comparison to non-social images, resulting in a later response for social stimuli. We expected that this difference in stability of image types was less pronounced in persons with ASD compared to control persons without ASD.

As previous studies suggested a mediating effect of the complexity of presented stimuli (Chita-Tegmark, 2016; Frazier et al., 2017; Guillon et al., 2014; Hamilton, 2016), we further explored potential shifts in the effects between images recognized earlier compared to those which were recognized later.

\section{Methods}

\section{Stimuli}

A subset of 120 images from de la Rosa et al. (2014) was rated by 33 participants ( 18 female, $M_{\text {age }} 26$ years, $\mathrm{sd}=5.6$ years) in an online study on the perceived degree of social content. Participants rated whether objects or persons were more prominent on a 5 -point Likert scale $(1=$ object to $5=$ person). The 25 highest and lowest scoring images were selected as "social" $\left(\mathrm{M}_{\text {score }} 4.94, \mathrm{sd}=0.09\right)$ or respectively "non-social" $\left(\mathrm{M}_{\text {score }} 1.20, \mathrm{sd}=0.30\right)$ and merged to hybrid images by an in-house developed algorithm (based on MATLAB (R2017a, MathWorks ${ }^{\circledR}$, Natick, MA). The pixels in each case were extracted in an alternating manner from two original images of the different categories. Then the extracted pixels were merged and arranged in a checkerboard order, resulting in hybrid images that combine $50 \%$ original pixels each from images of the two categories. As pixels of the initial images are merged in an alternating manner, the recognizability of one image simultaneously disturbs the recognizability of the other one. However, it is possible to control each portion separately and specifically because of the underlying regular checkerboard pattern. A systematic rearrangement of the pixel values of the one or the other source allows a controlled vanishing by stepwise randomization or respectively re-emergence of either the one or the other image. Hence, either the image from the social or the non-social category (Fig. 1) emerged.

It is important to note that only the spatial arrangement of the pixel values is changed. Any change of pixel locations modifies the recognizable content, whereas the mean gray values of the images as a whole and gray value histograms do not change.
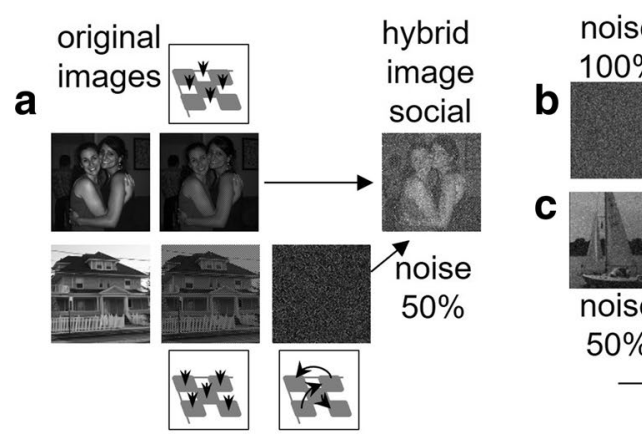

Fig. 1 Illustration of the algorithm. a A pair of images (social, nonsocial) is selected. Both images lose half of their informative pixels in a checkerboard- style, to produce a hybrid image. The pixel values of one image (here: the house) are randomized before being combined with pixels of the other image (here: two persons). In the social hybrid image, the information of the social image is preserved whereas the object information of the non-social image is lost. The

transformation from the image displaying the house to the image with the random pattern is achieved by spatially re-arranging of the pixels. Please note, that both mean gray values and graytone histograms of all images remain the same. b Systematic "emergence" of a social image from noise in the recognition task over $8 \mathrm{~s}$. c Systematic "dissipation" of a non-social image into noise in the persistence task 


\section{Participants}

26 persons without a diagnosis of ASD (CON; $\mathrm{M}_{\text {age }}=34.15$ years, $\mathrm{sd}=10.89$ years, 13 female) and 23 persons with ASD (ASD; $M_{\text {age }}=41.26$ years, $\mathrm{sd}=8.93$ years, 7 female) diagnosed at the outpatient clinic of the University Hospital Cologne participated in the experiment.

Participants with ASD were screened with common self-report instruments (AQ, EQ see Table 1), invited to $2-3$ clinical interviews, conducted by at least 2 different professional clinicians according to the criteria of the WHO (ICD-10). A prerequisite for participation in the experiment was the exclusion of learning disabilities or impairments of intelligence (IQ $>=85,(\mathrm{M}=111.82$, $\mathrm{SD}=18.15$ ) or qualification/degree from university), and the exclusion of clinical depression (BDI $>19$, see Table 1) to avoid any distortions of cognitive processes required by the task instructions. All participants with ASD were fully verbal autistic adults. The sample size was limited by the number of persons with ASD, that were willing to participate and fulfilled the inclusion criteria. Education years did not differ between both groups (see Table 1). We chose person-first language to designate the participants in the study (Tepest, 2021). Groups did systematically differ in age ( $\mathrm{t}$-test for independent samples, $\left.\mathrm{t}_{(47)}=2.51, \mathrm{p}=0.02\right)$.

\section{Procedure}

Participants underwent the recognition task first, followed by the persistence task. Each stimulus video was presented once per task, resulting in 100 trials per participant. Stimuli (resolution of $300 * 300$ pixel) were presented centrally on a 23 " monitor, participants were seated at approximate $60 \mathrm{~cm}$ distance for an image size of 7.6*7.6 degrees visual angle.

Table 1 Demographic and questionnaire variables including age, education years, AQ, EQ, BDI values

\begin{tabular}{lllll}
\hline & CON & ASD & $\mathrm{t}$ & $\mathrm{p}$ \\
\hline Age (years) & $\begin{array}{c}34.153 \\
(10.894)\end{array}$ & $41.625(8.930)$ & 2.507 & $.016^{*}$ \\
& & & \\
$\begin{array}{c}\text { Education } \\
\text { (years) }\end{array}$ & $17.02(4.912)$ & $17.864(4.215)$ & 0.63 & 0.53 \\
AQ values & 12.885 & $39.609(5.366)$ & 18.0 & $<.001^{* * *}$ \\
& $(4.982)$ & & & \\
EQ values & $44.68(9.182)$ & $16.391(8.574)$ & -11.037 & $<.001^{* * *}$ \\
BDI values & $3.72(3.518)$ & $7.0(5.394)$ & 2.473 & $.0181^{*}$ \\
\hline
\end{tabular}

Group means and standard deviations are reported, including t-values and significance levels $(.<.1, *<.05, * *<.01, * * *<.001)$

\section{Recognition Task}

Starting with a hybrid image with all pixels shuffled (100\% noise), the pixels from one of the two composite images were subsequently re-arranged letting this image emerge over the course of $8 \mathrm{~s}$ (Fig. 1b). The participants were instructed to press the space key as soon as they were aware of what was depicted in the image. The image would then disappear. To ensure task compliance, the participants were asked to indicate the stimulus content via button press $(1=$ one person, $2=$ several persons, $3=$ animal, $4=$ inanimate object).

\section{Persistence Task}

Trials started with hybrid images with 50\% noise (i.e., randomly shuffled pixels of one of the two composite images, the other of the two composite images being arranged correctly). Subsequently, the correctly ordered pixels were shuffled incrementally over the course of $8 \mathrm{~s}$, too, so that the visible image dissipated into noise (see Fig. 1c). During the increase in noise participants were instructed to indicate via space-key press the moment in time when the image became unrecognizable.

\section{Analysis}

We used R (R Core Team, 2012) and lme4 (Bates et al., 2012) to perform a linear mixed effects analysis of the relationship between social and non-social images and response time in the two different perception tasks for both diagnostic groups. As fixed effects, we entered group (ASD vs. CON) and image type (social vs. non-social) with interaction-term into the model. As random effect, we included intercepts for subjects. Visual inspection of residual plots did not reveal any obvious deviations from homoscedasticity or normality. P-values were obtained by likelihood ratio tests of the full model with the effect in question against the model without the effect in question. Estimates are reported as means and standard errors. As an approximation for effect sizes we report delta total, $d_{t}$ (Brysbaert \& Stevens, 2018; Westfall et al., 2014).

Starting with 53 participants we excluded data from one control person who had an AQ value above the threshold of 32. Furthermore, we excluded data from two participants with ASD who had a BDI score above the threshold of 19 , resulting in 49 participants (ASD: $n=23$; CON: $\mathrm{n}=26$ ). All differences between groups were calculated using glm with Poisson link functions. We excluded trials in which no press of the space-key was recorded as missing data (recognition task: ASD 4.96\%, CON 2.77\%, $\mathrm{z}=-2.84 \mathrm{p}=0.004$; persistence task: ASD $1.22 \%$, $\mathrm{CON}=0.08 \%, \mathrm{z}=-2.67, \mathrm{p}=0.01)$. To account for accidental key presses, response times below one second were 
excluded from analysis (recognition task: ASD 0.0\%, CON $0.08, \mathrm{z}=0.003, \mathrm{p}=0.99$; persistence task: ASD 0.09\%, CON $0.23 \%, z=0.84, p=0.40$ ). Furthermore, we excluded inaccurately categorized trials from the recognition task (ASD $1.91 \%$, CON $1.31 \%, z=-1.18, p=0.24$ ). Finally, we excluded individual outliers, which were defined as recognition or persistence times that were above or below 2 standard deviations of the participant's individual average in that task (recognition task: ASD 3.74\%, CON $4.54 \%, \mathrm{z}=0.97, \mathrm{p}=0.33$; persistence task: ASD $4.52 \%$, CON $3.62 \%, z=-1.21, p=0.226$ ).

\section{Exploratory Analysis}

To investigate whether the degree of complexity of images had the same effect on recognition in the social and non-social categories we ranked the stimuli according to their average response time and split them into an "early responses"(12 stimuli) and a "late responses" (13 stimuli) subset (average difference $1.557 \mathrm{~s}$, se $=0.08 \mathrm{~s}$ ). The ranking was highly consistent in both groups, resulting in high correlations of average recognition times per stimulus between diagnostic groups for social $(r=0.982$ $\left.[0.959 ; 0.992], \mathrm{t}_{(23)}=25.013, \mathrm{p}<0.001\right)$ and non-social stimuli $\left(\mathrm{r}=0.951[0.889 ; 0.978], \mathrm{t}_{(23)}=14.675, \mathrm{p}<0.001\right)$. The effect of response subsets and its interactions with other factors were tested in likelihood ratio tests of linear models. Subsequently, we also compared the recognition response times of the diagnostic groups quantile-wise for the different levels of complexity via the shift-function of the rogme package (Rousselet \& Wilcox, 2020).

\section{Results}

\section{Effects of Age and Gender}

To investigate possible effects of age and gender we analyzed both diagnostic groups separately. Neither in the CON group nor the ASD group any of the factors age and gender showed an increased model fit in any of the two tasks [CON recognition task: age $\left(\chi_{(1)}^{2}=0.503, \mathrm{p}=0.50\right)$, gender $\left(\chi_{(1)}^{2}=1.618, \mathrm{p}=0.20\right)$; ASD recognition task: age $\left(\chi_{(1)}^{2}=0.505, \mathrm{p}=0.48\right)$, gender $\left(\chi_{(1)}^{2}=0.749, \mathrm{p}=0.39\right)$; CON persistence task: age $\left(\chi_{(1)}^{2}=0.704, \mathrm{p}=0.40\right)$, gen$\operatorname{der}\left(\chi_{(1)}^{2}=0.023, \mathrm{p}=0.88\right)$; ASD persistence task: age $\left(\chi_{(1)}^{2}=0.001, p=0.98\right)$, gender $\left.\left.\chi_{(1)}^{2}=2.117, p=0.15\right)\right]$. Hence, we found no support for influences of age or gender onto recognition or persistence times.

\section{Recognition Task}

Belonging to group ASD significantly increased the recognition time by $0.382 \mathrm{~s}(\mathrm{se}=0.16 \mathrm{~s})\left(\chi_{(1)}^{2}=6.365, \mathrm{p}=0.012\right.$, $\left.d_{t}=-0.299[-0.543 ;-0.056]\right)$. Social stimuli significantly lowered recognition time by $0.423 \mathrm{~s}(\mathrm{se}=0.07 \mathrm{~s})$, $\left(\chi_{(1)}^{2}=74.760, p<0.001, d_{t}=-0.335[-0.448 ;-0.222]\right)$. There was no significant interaction of group and image type $\left(\chi_{(1)}^{2}=0.028, p=0.867, d_{t}=-0.013[-0.168 ; 0.141]\right.$, see Fig. 2a).

\section{Persistence Task}

Belonging to group CON did not affect persistence time $\left(\chi_{(1)}^{2}=2.133, p=0.14, d_{t}=-0.290[-0.662 ; 0.082]\right)$.
Fig. 2 Response times across diagnostic groups and image type during "emergence" of the images. Individual participant's average response times are depicted by small, filled circles, group averages are depicted by big open circles. Responses on social images are shown in red, responses on non-social ones in blue. a Recognition times for the complete data set. b Recognition times split into two subsets of early responses and late responses. c Persistence times during "dissipation" back into noise. Persistence times for the complete data set

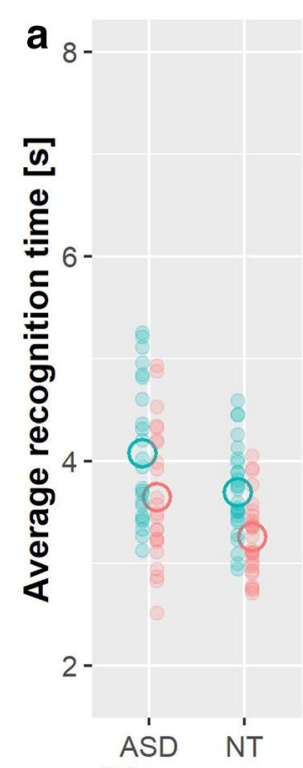

Diag. group
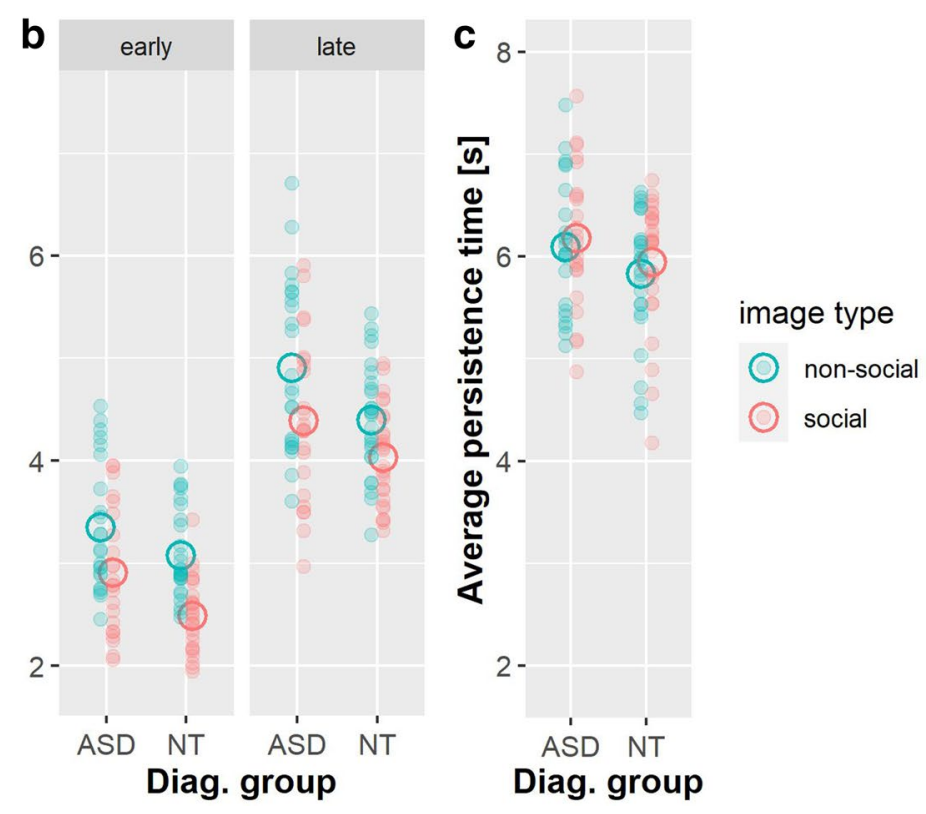
Social stimuli increased persistence time by about $0.089 \mathrm{~s}$ $(\mathrm{se}=0.044 \mathrm{~s})\left(\chi_{(1)}^{2}=11.689, \mathrm{~d}_{\mathrm{t}}=0.093\right.$ [0.002;0.185], $\mathrm{p}<0.001)$. There was no significant interaction of group and image type $\left(\chi_{(1)}^{2}=0.199, \mathrm{p}=0.66, \mathrm{~d}_{\mathrm{t}}=0.028[-0.096\right.$; 0.153], see Fig. 2c).

\section{Exploratory Analysis}

The introduction of a three-way interaction of response subset*image type* group significantly improved the model fit $\left(\chi_{(1)}^{2}=3.862, p=0.049, d_{t}=-0.294[0.001 ; 0.587]\right)$ compared to all models including single interactions with an estimate (group CON, late, social) of $0.307 \mathrm{~s}$ ( $\mathrm{se}=0.16 \mathrm{~s}$ ). In social stimuli, group differences appeared larger in early compared to late responses while in non-social stimuli, group differences appeared smaller for early compared to late responses (Fig. 2b). Separate post-hoc analyses of the early and late response subsets revealed no significant interactions of diagnostic group*image type (subset early $\chi_{(1)}^{2}=2.369, p=0.12$, subset late $\left.\chi_{(1)}^{2}=1.634, p=0.20\right)$.

However, a quantile-wise analysis (Fig. 3) elucidates the changes in the difference between diagnostic groups depending on the complexity of the stimuli, i.e., for early vs. late recognized images. These changes seem to have opposite directions for social and non-social stimuli with higher complexity leading to a decrease of group differences for social stimuli and an increase for non-social stimuli.

\section{Discussion}

In the current study we compared the performance of persons with and without ASD differentiating between social and non-social stimuli in two different perceptual tasks.
Social stimuli were recognized significantly faster than non-social stimuli by both groups, as described by previous reports of preferential processing of social over non-social stimuli (Bruce et al., 1991; Kikuchi et al., 2009; Lehky, 2000; Ro et al., , 2001, 2007). This is also in accordance with neuroscientific evidence of pathways specialized for the processing of socially relevant information (Alcalá-López et al., 2018; Nummenmaa \& Calder, 2009).

Participants with ASD were generally slower to respond to emerging stimuli. This delay to recognize social and nonsocial images might be explained by the fact that global, semantic processing is essential for our task. Individuals with ASD have been reported to perceive global order or the gist of a scene slower compared to CON (Van der Hallen et al., 2015; Vanmarcke et al., 2016a, 2016b). This could also be interpreted in the context of difficulties in persons with ASD in gestalt processing (Bölte et al., 2007; Brosnan et al., 2004; Gowen et al., 2020). Relatedly, the increased response times observed in individuals with ASD may correspond to differences in central coherence (Brock et al., 2002; Frith, 2003; Happé, 1999). Weak central coherence theory states that behavioral symptoms of ASD are exhibited due to the comparatively low integration of complex sensory information, with more pronounced focus on detail than on context. We instructed participants to perform a task which required persistent integration of changing stimuli. Considering the assumed differences in information integration for persons with ASD, solving this task would require more time as compared to persons without ASD. The latter group would perceive the changing picture as changing globally, with the presented picture as a continuous and synchronous, stable percept. Conversely, perceptual processing in the ASD group would be directed at the pixel changes more locally, merging these changes into a coherent percept only

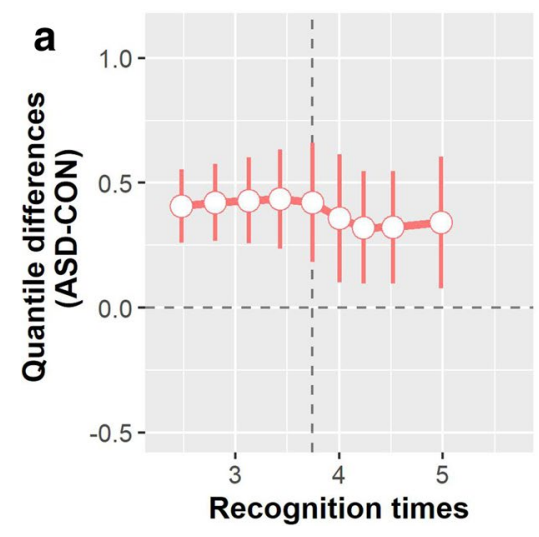

Fig. 3 Quantile-wise comparison of averaged recognition times for all social and non-social stimuli between diagnostic groups (shift function). The difference ASD-CON is depicted along the y-axis for each decile (white disks), as a function of ASD deciles. For each decile difference, the vertical line indicates its $95 \%$ bootstrap confidence

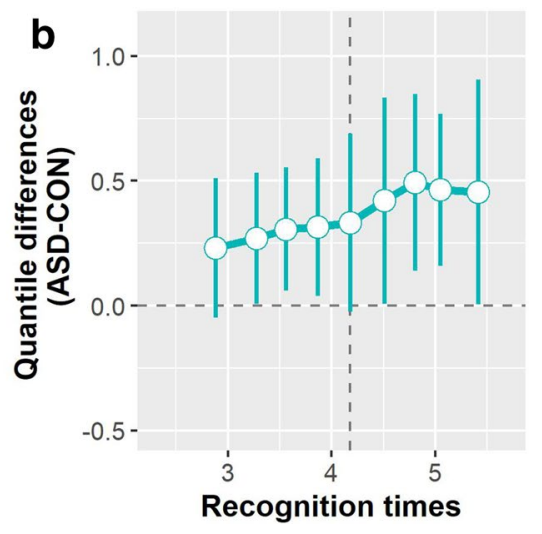

interval. When a confidence interval does not include zero, the difference is considered significant in a frequentist sense. a Shift function for the emergence of social stimuli. b Shift function for the emergence of non-social stimuli 
afterwards; hence requiring more time. These considerations relate to recent theory on the importance of time and temporal processing in the emergence of autistic symptoms in persons with ASD, when faced with interactive and social situations (Bloch et al., 2019; Hohwy et al., 2016; Vogel et al., 2019). This idea is further corroborated by neither findings of general impairments in reaction times in persons with ASD (Ferraro, 2016), nor findings of visual perception being slower or less accurate than in persons without ASD per se (Remington et al., 2009; Vanmarcke et al., 2016b).

A potential caveat of the recognition task is that social stimuli (depicting people) might be less heterogeneous than non-social images and are more frequently presented. This could have biased attention and could have facilitated the recognition of social stimuli. However, in the persistence task, all stimuli were already familiar and visible in the beginning of the trial, thus minimizing attention and homogeneity biases. Here, again, social stimuli seem to have been recognizable baring higher levels of noise (i.e. social stimuli were recognizable longer). Thus, the persistence task further corroborates that social stimuli are indeed processed preferentially. Furthermore, although a recent meta-analysis suggests no general impairment, mixed findings exist regarding reaction times in ASD (Ferraro, 2016). Therefore, results from the persistence task also speak against a mere reaction time bias in ASD in the recognition task.

Results in the persistence task did not differ between diagnostic groups and thus did not indicate any general tendency towards response delay or increased avoidance of uncertainty in ASD. We also have no reason to assume that social scenes compared to non-social scenes persisted longer in control subjects compared to subjects with ASD. One explanation could be that control participants were superior in the automatic processing of social stimuli and that this was more decisive in the recognition task. Implicit and automatic features of social cognition have repeatedly been emphasized (Bargh, 1994; Choi et al., 2005) and it seems that these features are especially difficult for persons with ASD (Eigsti, 2013; McIntosh et al., 2006).

We did not find specific effects of social stimuli in persons with ASD. This stands in contrast to previous studies, reporting decreased attention for social stimuli in ASD. However, recently, the account of a general reduction in attention to social stimuli in ASD has been challenged (Guillon et al., 2016). Instead, it was argued that impairments in attention towards social stimuli in ASD seem to be dependent on the complexity and contextual factors of stimuli (Chita-Tegmark, 2016; Guillon et al., 2014; Hamilton, 2016). Following this proposal, we investigated in an exploratory analysis the effect of stimulus complexity on recognition times. Group differences in social images seemed to be generally more pronounced in low complexity stimuli and decreased with complexity while the opposite was true for non-social stimuli. Thus, the relationship between the social character and the complexity in the recognition of pictures in ASD requires further investigations.

In future studies, an in-depth analysis of the characteristics responsible for early or late recognition could enable a discussion in current frameworks, e.g. weak central coherence theory (Happé \& Booth, 2008; Happé \& Frith, 2006; Koldewyn et al., 2013) or alternatively the enhanced perceptual functioning account (Mottron et al., 2006). In particular, since recent meta-analyses have questioned general deficits in ASD global processing (Van der Hallen et al., 2015) but find delayed processing or a specificity in social images (Vanmarcke et al., 2016b), more detailed studies are required.

We did not find influences of age or gender in our tasks, which is in line with several meta-analyses that find a stable social attention bias between persons with ASD and control persons across ages and gender (Chita-Tegmark, 2016; Frazier et al., 2017). However, there is also evidence that the social attention bias might be more pronounced and homogenous in children in the age range of $0.5-5$ years (Guillon et al., 2014) and that results for children/adolescents (age range of 5-18 years) and adults are much more heterogeneous. It is very possible that persons with ASD learn to compensate for a social attention bias and that this task would have very different results in younger children.

In summary, our results showed that control subjects were faster in recognizing images compared to subjects with ASD. Both groups recognized social scenes, i.e., images containing persons, faster than images containing animals or objects. Contrary to our hypothesis, we did not find a general impairment in the recognition of social scenes in persons with ASD compared to control subjects. However, exploratory analyses suggested that the complexity of the depicted scenes might be experienced differently by subjects with and without ASD in social and non-social stimuli.

\section{Limitations}

The two diagnostic groups differ significantly in age by about 5 years ( $\mathrm{sd}=9$ years). However, separate analyses of the influence of age and gender did not point towards significant influences on the tasks. BDI scores were slightly higher in the ASD group compared to controls but none of these were above a clinically relevant threshold and the validity of these scores might be limited in persons with ASD (Cassidy et al., 2018). The generalizability of our findings might be limited, since our sample sizes were rather small and our sample of adult persons with ASD was very well educated and highly functioning. In other age groups or clinical populations, results might be different. 
Author Contributions MJ, YA, KV, and RT contributed to the study conception and design. Material preparation, data collection and analysis were performed by YA, DV, MJ, AM and RT. The first draft of the manuscript was written by AM and all authors commented on previous versions of the manuscript. All authors read and approved the final manuscript.

Funding Open Access funding enabled and organized by Projekt DEAL. No funding was received.

\section{Declarations}

Conflict of interest The authors have no relevant financial or non-financial interests to disclose.

Ethics Approval All procedures were approved by the ethics committee of the Medical Faculty of the University of Cologne and adhered to the tenets of the declaration of Helsinki as well as to the standards of good scientific practice.

Consent to Participate All participants gave informed written consent and were compensated with 10 Euro/h for their participation in the study.

Open Access This article is licensed under a Creative Commons Attribution 4.0 International License, which permits use, sharing, adaptation, distribution and reproduction in any medium or format, as long as you give appropriate credit to the original author(s) and the source, provide a link to the Creative Commons licence, and indicate if changes were made. The images or other third party material in this article are included in the article's Creative Commons licence, unless indicated otherwise in a credit line to the material. If material is not included in the article's Creative Commons licence and your intended use is not permitted by statutory regulation or exceeds the permitted use, you will need to obtain permission directly from the copyright holder. To view a copy of this licence, visit http://creativecommons.org/licenses/by/4.0/.

\section{References}

Alcalá-López, D., Smallwood, J., Jefferies, E., Van Overwalle, F., Vogeley, K., Mars, R. B., Turetsky, B. I., Laird, A. R., Fox, P. T., Eickhoff, S. B., \& Bzdok, D. (2018). Computing the social brain connectome across systems and states. Cerebral Cortex, 28(7), 2207-2232. https://doi.org/10.1093/cercor/bhx121

Bargh, J. A. (1994). The four horsemen auf automaticity: Awareness, intention, efficiency and control in social cognition. In R. Wyer \& T. Srull (Eds.), Handbook of social cognition. London: Lawrence Erlbaum.

Bates, D., Maechler, M., Bolker, B., Walker, S., Christensen, R., Singmann, H., \& Scheipl, F. (2012). Package 'lme4'. CRAN. R Foundation for Statistical Computing, Vienna, Austria.

Bloch, C., Vogeley, K., Georgescu, A. L., \& Falter-Wagner, C. M. (2019). INTRApersonal Synchrony as Constituent of INTERpersonal Synchrony and Its Relevance for Autism Spectrum Disorder. Frontiers in Robotics and A, I, 6. https://doi.org/10.3389/frobt. 2019.00073

Bölte, S., Holtmann, M., Poustka, F., Scheurich, A., \& Schmidt, L. (2007). Gestalt perception and local-global processing in high-functioning autism. Journal of Autism and Developmental Disorders, 37(8), 1493-1504. https://doi.org/10.1007/ s10803-006-0231-x
Brock, J., Brown, C. C., Boucher, J., \& Rippon, G. (2002). The temporal binding deficit hypothesis of autism. Development and Psychopathology, 14(2), 209-224.

Brosnan, M. J., Scott, F. J., Fox, S., \& Pye, J. (2004). Gestalt processing in autism: Failure to process perceptual relationships and the implications for contextual understanding. Journal of Child Psychology and Psychiatry, 45(3), 459-469. https://doi.org/10.1111/j. 1469-7610.2004.00237.x

Bruce, V., Doyle, T., Dench, N., \& Burton, M. (1991). Remembering facial configurations. Cognition, 38(2), 109-144. https://doi.org/ 10.1016/0010-0277(91)90049-A

Brysbaert, M., \& Stevens, M. (2018). Power analysis and effect size in mixed effects models: A tutorial. Journal of Cognition, 1(1), 9. https://doi.org/10.5334/joc.10

Cassidy, S. A., Bradley, L., Bowen, E., Wigham, S., \& Rodgers, J. (2018). Measurement properties of tools used to assess depression in adults with and without autism spectrum conditions: A systematic review. Autism Research, 11(5), 738-754. https://doi. org/10.1002/aur.1922

Chevallier, C., Huguet, P., Happé, F., George, N., \& Conty, L. (2013). Salient social cues are prioritized in autism spectrum disorders despite overall decrease in social attention. Journal of Autism and Developmental Disorders, 43(7), 1642-1651. https://doi.org/10. 1007/s10803-012-1710-x

Chita-Tegmark, M. (2016). Social attention in ASD: A review and meta-analysis of eye-tracking studies. Research in Developmental Disabilities, 48, 79-93. https://doi.org/10.1016/j.ridd.2015.10.011

Choi, Y. S., Gray, H. M., \& Ambady, N. (2005). The glimpsed world: Unintended communication and unintended perception. In R. R. Hassin, J. S. Uleman, \& J. A. Bargh (Eds.), The New Unconscious (pp. 309-333). Oxford: Oxford University Press.

Eigsti, I.-M. (2013). A review of embodiment in autism spectrum disorders. Frontiers in Psychology, 4, 224. https://doi.org/10.3389/ fpsyg.2013.00224

Ferraro, F. R. (2016). No evidence of reaction time slowing in autism spectrum disorder. Autism, 20(1), 116-122. https://doi.org/10. $1177 / 1362361314559986$

Frazier, T. W., Strauss, M., Klingemier, E. W., Zetzer, E. E., Hardan, A. Y., Eng, C., \& Youngstrom, E. A. (2017). A meta-analysis of gaze differences to social and nonsocial information between individuals with and without autism. Journal of the American Academy of Child \& Adolescent Psychiatry, 56(7), 546-555. https://doi.org/ 10.1016/j.jaac.2017.05.005

Frith, U. (2003). Autism: Explaining the enigma (Six, 249) (2nd ed.). London: Blackwell.

Gowen, E., Jachim, S., Subri, S., Dickinson, C., Hamblin-Pyke, B., \& Warren, P. A. (2020). Collinear facilitation and contour integration in autistic adults: Examining lateral and feedback connectivity. Vision Research, 177, 56-67. https://doi.org/10.1016/j.visres. 2020.08.004

Guillon, Q., Hadjikhani, N., Baduel, S., \& Rogé, B. (2014). Visual social attention in autism spectrum disorder: Insights from eye tracking studies. Neuroscience \& Biobehavioral Reviews, 42, 279-297. https://doi.org/10.1016/j.neubiorev.2014.03.013

Guillon, Q., Rogé, B., Afzali, M. H., Baduel, S., Kruck, J., \& Hadjikhani, N. (2016). Intact perception but abnormal orientation towards face-like objects in young children with ASD. Scientific Reports, 6(1), 22119. https://doi.org/10.1038/srep22119

de Hamilton, A. F. (2016). Gazing at me: The importance of social meaning in understanding direct-gaze cues. Philosophical Transactions of the Royal Society b: Biological Sciences, 371(1686), 20150080. https://doi.org/10.1098/rstb.2015.0080

Happé, F. (1999). Autism: Cognitive deficit or cognitive style? Trends in Cognitive Sciences, 3(6), 216-222. https://doi.org/10.1016/ S1364-6613(99)01318-2 
Happé, F., \& Booth, R. (2008). The power of the positive: Revisiting weak coherence in autism spectrum disorders. Quarterly Journal of Experimental Psychology, 61(1), 50-63. https://doi.org/10. 1080/17470210701508731

Happé, F., \& Frith, U. (2006). The weak coherence account: Detailfocused cognitive style in autism spectrum disorders. Journal of Autism and Developmental Disorders, 36(1), 5-25. https://doi. org/10.1007/s10803-005-0039-0

Hohwy, J., Paton, B., \& Palmer, C. (2016). Distrusting the present. Phenomenology and the Cognitive Sciences, 15(3), 315-335. https://doi.org/10.1007/s11097-015-9439-6

Jiang, Y., Costello, P., \& He, S. (2007). Processing of invisible stimuli: Advantage of upright faces and recognizable words in overcoming interocular suppression. Psychological Science, 18(4), 349-355. https://doi.org/10.1111/j.1467-9280.2007.01902.x

Kikuchi, Y., Senju, A., Tojo, Y., Osanai, H., \& Hasegawa, T. (2009). Faces do not capture special attention in children with autism spectrum disorder: A change blindness study. Child Development, 80(5), 1421-1433. https://doi.org/10.1111/j.1467-8624. 2009.01342.x

Koldewyn, K., Jiang, Y. V., Weigelt, S., \& Kanwisher, N. (2013). Global/local processing in autism: Not a disability, but a disinclination. Journal of Autism and Developmental Disorders, 43, 2329-2340.

Lehky, S. R. (2000). Fine discrimination of faces can be performed rapidly. Journal of Cognitive Neuroscience, 12(5), 848-855. https:// doi.org/10.1162/089892900562453

McIntosh, D. N., Reichmann-Decker, A., Winkielman, P., \& Wilbarger, J. L. (2006). When the social mirror breaks: Deficits in automatic, but not voluntary, mimicry of emotional facial expressions in autism. Developmental Science, 9(3), 295-302. https://doi.org/ 10.1111/j.1467-7687.2006.00492.x

Mottron, L., Dawson, M., Soulières, I., Hubert, B., \& Burack, J. (2006). Enhanced perceptual functioning in autism: An update, and eight principles of autistic perception. Journal of Autism and Developmental Disorders, 36(1), 27-43. https://doi.org/10.1007/ s10803-005-0040-7

Nummenmaa, L., \& Calder, A. J. (2009). Neural mechanisms of social attention. Trends in Cognitive Sciences, 13(3), 135-143. https:// doi.org/10.1016/j.tics.2008.12.006

Purcell, D. G., \& Stewart, A. L. (1988). The face-detection effect: Configuration enhances detection. Perception \& Psychophysics, 43(4), 355-366. https://doi.org/10.3758/BF03208806

Remington, A., Swettenham, J., Campbell, R., \& Coleman, M. (2009). Selective attention and perceptual load in autism spectrum disorder. Psychological Science, 20(11), 1388-1393. https://doi.org/ 10.1111/j.1467-9280.2009.02454.x

Ro, T., Friggel, A., \& Lavie, N. (2007). Attentional biases for faces and body parts. Visual Cognition, 15(3), 322-348. https://doi.org/10. 1080/13506280600590434
Ro, T., Russell, C., \& Lavie, N. (2001). Changing faces: A detection advantage in the flicker paradigm. Psychological Science, 12(1), 94-99. https://doi.org/10.1111/1467-9280.00317

de la Rosa, S., Choudhery, R. N., Curio, C., Ullman, S., Assif, L., \& Bülthoff, H. H. (2014). Visual categorization of social interactions. Visual Cognition, 22(9-10), 1233-1271. https://doi.org/10. 1080/13506285.2014.991368

Rousselet, G. A., \& Wilcox, R. R. (2020). Reaction times and other skewed distributions: Problems with the mean and the median. Meta-Psychology. https://doi.org/10.15626/MP.2019.1630

Tang, J., Falkmer, M., Horlin, C., Tan, T., Vaz, S., \& Falkmer, T. (2015). Face recognition and visual search strategies in autism spectrum disorders: Amending and extending a recent review by Weigelt et al. PLoS ONE, 10(8), e0134439. https://doi.org/10. 1371/journal.pone.0134439

Tepest, R. (2021). The meaning of diagnosis for different designations in talking about autism. Journal of Autism and Developmental Disorders, 51, 760-761. https://doi.org/10.1007/ s10803-020-04584-3

Van der Hallen, R., Evers, K., Brewaeys, K., den Noortgate, W. V., \& Wagemans, J. (2015). Global processing takes time: A metaanalysis on local-global visual processing in ASD. Psychological Bulletin, 141(3), 549-573. https://doi.org/10.1037/bul0000004

Vanmarcke, S., Mullin, C., Van der Hallen, R., Evers, K., Noens, I., Steyaert, J., \& Wagemans, J. (2016a). In the eye of the beholder: Rapid visual perception of real-life scenes by young adults with and without ASD. Journal of Autism and Developmental Disorders, 46(8), 2635-2652. https://doi.org/10.1007/ s10803-016-2802-9

Vanmarcke, S., Van Der Hallen, R., Evers, K., Noens, I., Steyaert, J., \& Wagemans, J. (2016b). Ultra-rapid categorization of meaningful real-life scenes in adults with and without ASD. Journal of Autism and Developmental Disorders, 46(2), 450-466. https://doi.org/10. 1007/s10803-015-2583-6

Vogel, D., Falter-Wagner, C. M., Schoofs, T., Krämer, K., Kupke, C., \& Vogeley, K. (2019). Interrupted time experience in autism spectrum disorder: Empirical evidence from content analysis. Journal of Autism and DevelopmentAl Disorders, 49(1), 22-33. https://doi. org/10.1007/s10803-018-3771-y

Weigelt, S., Koldewyn, K., \& Kanwisher, N. (2013). Face recognition deficits in autism spectrum disorders are both domain specific and process specific. PLOS ONE, 8(9), e74541. https://doi.org/ 10.1371/journal.pone.0074541

Westfall, J., Kenny, D. A., \& Judd, C. M. (2014). Statistical power and optimal design in experiments in which samples of participants respond to samples of stimuli. Journal of Experimental Psychology: General, 143(5), 2020-2045. https://doi.org/10.1037/xge00 00014

Publisher's Note Springer Nature remains neutral with regard to jurisdictional claims in published maps and institutional affiliations. 